\title{
CD39 Modulates Endothelial Cell Activation and Apoptosis
}

\author{
Christian Goepfert, Masato Imai, Sophie Brouard, Eva Csizmadia, \\ Elzbieta Kaczmarek, and Simon C. Robson \\ Center for Immunobiology, Department of Medicine, Beth Israel Deaconess Medical \\ Center, Harvard Medical School, Boston, Massachusetts, U.S.A.
}

Accepted April 23, 2000

\begin{abstract}
Background: CD39 is the dominant vascular nucleoside triphosphate diphosphohydrolase (NTPDase) that exerts major effects on platelet reactivity by the regulated hydrolysis of extracellular adenine nucleotides. The effects of NTPDases on endothelial cell (EC) activation and apoptosis remain unexplored.

Material and Methods: Recombinant replicationdeficient adenoviruses were constructed with human CD39 cDNA (rAdCD39) or the bacterial $\beta$-galactosidase (rAd $\beta$ gal).

Results: Intact human umbilical vein EC cultures infected with rAdCD39 had substantial and stable increases in NTPDase biochemical activity (14.50 \pm 3.50 $\mathrm{Pi}$ nmole/well/min), when contrasted with noninfected cells $(0.95 \pm 0.002)$ and $\mathrm{rAd} \beta$ gal infected cells
\end{abstract}

$(1.01 \pm 0.02 ; p<0.005)$. Increased NTPDase activity efficiently inhibited immediate type $2 \mathrm{Y}$ purinergic receptor (P2Y)-mediated EC activation responses viz. von Willebrand factor secretion in response to extracellular ATP. In addition, CD39 up-regulation blocked ATP-induced translocation of the transcription nuclear factor $(\mathrm{NF})-\kappa \mathrm{B}$ to the cell nucleus, and abrogated transcription of mRNA encoding E-selectin, and consequent protein synthesis. CD39 also decreased the extent of apoptosis triggered by putative type- $2 \mathrm{X}$ purinergic $(\mathrm{P} 2 \mathrm{X} 7)$ receptors in response to high concentrations of extracellular ATP in vitro.

Conclusion: These properties of CD39 indicate primary vascular protective effects with potential therapeutic applications.

\section{Introduction}

The vascular nucleoside triphosphate diphosphohydrolase (NTPDase; EC 3.5.1.5 or CD39) is expressed on the luminal surface and caveolar microdomains of endothelial cells (EC) (1). Vascular CD39 sequentially hydrolyses extracellular plasma ATP and ADP to the monophosphate derivative AMP (2-5). CD73 (ecto-5'-nucleotidase; EC 3.1.3.5) associates with the vasculature, then generates adenosine from the adenosine monophosphate (6). Adenosine reacts with specific receptors in the vasculature, on leukocytes, or on platelets, and is taken up by EC via concentrative transporters

Address correspondence and reprint requests to: Dr. Simon C. Robson, Rm. 370 H, Research North, Beth Israel Deaconess Medical Center, 99 Brookline Avenue, Boston, MA 02215, U.S.A. Phone: 617-632-0881; Fax: 617-632-0880; E-mail: srobson@caregroup.harvard.edu
(7-9). These ectonucleotidases and related proteins are wholly responsible for the chain of extracellular nucleotide hydrolysis in the blood (5).

Both ATP and ADP are released at high concentrations from activated platelets and injured EC $(10,11)$. These extracellular nucleotides bind to and activate specific purinergic type 2 (P2) receptors expressed on EC (12). $\mathrm{P} 2 \mathrm{Y}$ receptors are G-protein-coupled proteins; whereas, P2X family members are ligand-gated channels (7). Following exposure to adenine nucleotides, EC undergo immediate activation responses with release of prestored proteins, such as von Willebrand factor (vWF) (13), with secretion of prostacyclin and nitric oxide (NO) (12). Ligation of $\mathrm{P} 2 \mathrm{Y}$ receptors results in the release of vWF stored in Weibel Palade bodies; whereas, adenosine can potentiate this effect via binding to the specific adenosine or Pl receptors (13). These early events are designated 
type I activation and do not require protein synthesis $(14,15)$.

Delayed or type II EC responses are generally regulated at the transcriptional level and consist of de novo synthesis and expression of a variety of proteins, including adhesion proteins such as E-selectin, proinflammatory cytokines such as IL-1 or monocyte chemoattractant protein-1 (MCP-1), and procoagulant molecules such as tissue factor $(16,17)$. These latter pathways are usually dependent on the nuclear translocation of the transcription nuclear factor NF- $\kappa \mathrm{B}(18,19)$, that can be induced by distinct P2 receptor activation responses $(20,21)$. Extracellular ATP also induces apoptotic cell death through interactions with the P2X7 purinergic receptor (22).

The regulated hydrolysis of adenine nucleotides and generation of nucleosides by the vascular NTPDase has potential implications for proximate ADP-mediated platelet reactivity (23-25). We demonstrated such thromboregulatory effects by the generation of mutant mice deficient in $c d 39$ (26). Somewhat paradoxically, these mice have defects in hemostasis associated with platelet P2Y1-type desensitization that is comparable to that seen in the recently described P2Y1-deficient mice (27). Mechanisms underlying the disordered vascular EC tissue factor expression, and consequent high levels of fibrin sequestration in the cd39-deficient mice, are under further investigation $(26,28)$.

CD39-associated NTPDase activity is also rapidly lost with graft rejection (29), ischemiareperfusion injury (30), oxidant perturbation $(2,31)$ and in cytokine-mediated EC activation responses (25). Such inflammatory changes commonly are associated with extensive vascular injury with the involvement of other mechanisms in vivo $(32,33)$. Multiorgan vascular injury is also observed in cd39-null mice, compared with wild-type mice (27). Excessive murine graft rejection reactions and organ failure also appear to be linked to the suppression or deletion of NTPDase expression [(26); unpublished data]. In addition, supplementation of cellular NTPDase activity by the infusion of apyrases effectively blocks platelet sequestration at the sites of vascular injury within cardiac grafts (34).

The aim of this study was to investigate any putative benefits of high-level expression of CD39 in the modulation of inflammatory responses in EC exposed to purinergic mediators. We present clear evidence that CD39 can down-regulate adenine nucleotide induced type I and type II EC activation and influence the process of ATP-induced apotosis. These experimental observations have important implications for the pharmacological use of CD39 in vascular inflammatory and thrombotic states.

\section{Materials and Methods}

\section{Cell Culture and Reagents}

Human umbilical vein endothelial cells (HUVEC) were kindly provided by Dr. Ewenstein, Brigham and Women's Hospital, Harvard Medical School, and maintained in M199 medium (BioWhittacker, Walkersville, MD) supplemented with $15 \%$ fetal calf serum (FCS; Atlanta Biologicals, Norcross, GA), $\mathrm{NaH}_{2} \mathrm{CO}_{3}$ (20mM), N-2-hydroxyethylpiperazine-N-2 ethanesulfonic acid (HEPES; 25mM), glutamine (5mM; BioWhittacker), heparin (100 $\mu \mathrm{g} / \mathrm{mL})$, gentamicin $(50 \mu \mathrm{g} / \mathrm{mL})$, and endothelial growth factor $(50 \mu \mathrm{g} / \mathrm{ml}$; Biomedical Technologies, Stoughton, MA). Cells were used up to the third passage, as described before (25). All reagents were analytical grade and purchased from Sigma (St. Louis, MO), unless otherwise stated.

\section{Adenoviral Vectors}

The replication defective adenovirus type $\mathrm{V}$ (a kind gift of Dr. Gerard, Univ. Texas, Southwestern Medical Center, Dallas, TX) was used to generate recombinant vectors. The adenoviruses used to overexpress CD39 contained the specific human cDNA (2), under the control of a cytomegalovirus promoter enhancer and an SV40 poly-adenylation sequence. This adenoviral vector, designated rAdCD39, was created by homologous recombination in 293 cells, between an El shuttle vector and the plasmid pJM17 containing the full adenoviral genome (35). The control adenovirus contained Escherichia coli $\beta$-galactosidase driven by the cytomegalovirus promoter was also a gift of Dr. Gerard, and was termed $\operatorname{rAd} \beta$ gal. This was used as a control for the effects of viral infection. Recombinant viruses were propagated in 293 cells and then isolated and purified. Viral titres were determined by the average of two plaque assays and expressed as plaque forming unit per $\mathrm{ml}(\mathrm{pfu} / \mathrm{ml})$, by standard convention (35). Virus stocks were expanded as previously described, aliquoted in small volumes, and stored in phosphate-buffered saline (PBS) with 10\% 
glycerol at $-80^{\circ} \mathrm{C}$. The viral titres used for these experiments ranged from $10^{10}-10^{13} \mathrm{pfu} / \mathrm{ml}$.

\section{Adenoviral-mediated Gene Transfer to EC}

HUVEC were infected with 100 pfu/cell. Adenoviral infection was carried out in 1\% FCS Dulbecco's modified Eagle's medium (DMEM) for $1.5 \mathrm{hr}$ at $37^{\circ} \mathrm{C}$, under $5 \% \mathrm{CO}_{2}$ and $95 \%$ humidity, with gentle shaking on a rocking platform. The FCS concentration was then adjusted to $10 \%$ and infected HUVEC were kept in the presence of the recombinant adenovirus for a further $48 \mathrm{hr}$. The culture medium was changed prior to formal experimentation. Further studies were carried out with infected cells 2 days after infection, to facilitate maximal protein expression.

\section{NTPDase Activity Assay}

Membrane-bound NTPDase activity was determined by measuring the amount of liberated inorganic phosphate hydrolyzed from exogenous, extracellular ATP (2). HUVEC were grown to confluence in 24-well plates, left untreated, or infected with $\mathrm{rAdCD} 39$ or $\operatorname{rAd} \beta$ gal for $48 \mathrm{hr}$. Intact HUVEC were incubated in $20 \mathrm{mM}$ Tris $\mathrm{pH} 8.0$ containing $5 \mathrm{mM} \mathrm{CaCl}_{2}$, and either $200 \mu \mathrm{M}$ ADP or $200 \mu \mathrm{M}$ ATP for 15 $\min$ at $37^{\circ} \mathrm{C}$. Release of free phosphate was then determined using published methodology (36). $5 \mathrm{mM}$ tetramisole was added to inhibit ecto-alkaline phosphatase in these assays. A standard curve was constructed using 0-20 $\mu \mathrm{M}$ $\mathrm{KH}_{2} \mathrm{PO}_{4}$. Malachite green was added to stop the reaction and absorbance at $610 \mathrm{~nm}$ was measured to determine phosphate levels against the standard curves.

\section{von Willebrand Factor (nWF) ELISA}

HUVEC were grown to confluence in 24-well plates, left untreated, or infected with rAdCD 39 or $\operatorname{rAd} \beta$ gal for $48 \mathrm{hr}$. Confluent cells were washed three times with Krebs-Ringer bicarbonate buffer $(120 \mathrm{mM} \mathrm{NaCl}, 1.2 \mathrm{mM}$ $\mathrm{CaCl}_{2}, 4.74 \mathrm{mM} \mathrm{KCl}, 1.2 \mathrm{KH}_{2} \mathrm{PO}_{4}, 0.6 \mathrm{mM}$ $\mathrm{MgSO}_{4}, 25 \mathrm{mM} \mathrm{NaHCO}$ and $25 \mathrm{mM}$ HEPES, pH 7.4), and then stimulated with either thrombin, ATP, the non-hydrolysable analog ATP $\gamma S$, or adenosine, in defined ranges and concentrations to elicit approximately $50 \%$ of maximal responses. Conditioned serum-free harvest fluids were obtained from HUVEC after 0,30 and $60 \mathrm{~min}$ post-stimulation. Then $100 \mu \mathrm{l}$ of test sample or vWF standard were added to a 96-well plate precoated with polyclonal goat anti-vWF (American Diagnostica, Greenwich, CT) and incubated for $1 \mathrm{hr}$ on a shaker at room temperature. After washing wells four times with phosphate buffered saline/tween (as provided by American Diagnostics), $100 \mu \mathrm{l}$ of horseradish peroxidase conjugated vWF antibody was added and incubated for $\mathrm{l} \mathrm{hr}$ at room temperature on a shaker. After washing four times with PBST, $100 \mu \mathrm{l}$ of substrate solution was added. The enzymatic reaction was stopped after $20 \mathrm{~min}$ by adding $50 \mu \mathrm{l}$ of $0.5 \mathrm{M}$ sulfuric acid. Absorbance was read on a micro-test plate reader (Biotek Instruments, Winooski, VT) at a wavelength of $450 \mathrm{~nm}$.

\section{E-selectin Cell ELISA}

HUVEC were grown to confluence in 96-well plate, left untreated, or infected with rAdCD39 or $\mathrm{rAd} \beta \mathrm{gal}$ for $48 \mathrm{hr}$, and then stimulated with thrombin, ATP $\gamma \mathrm{S}$, ATP or adenosine (ADO) for $12 \mathrm{hr}(20,22)$. Cells were washed three times with PBS and fixed with $0.05 \%$ glutaraldehyde in PBS for 10 min on ice, then blocked with $1 \%$ FCS PBS for $1 \mathrm{hr}$ at room temperature. Cells were washed three times with PBS and incubated with a mouse monoclonal antibody BBAl (R\&D Systems, Minneapolis, MN) directed against human E-selectin, for $\mathrm{l} \mathrm{hr}$ at room temperature. Cells were washed three times with PBS and a goat anti-mouse horseradish peroxidase-coupled polyclonal antibody (Pierce, Rockford, IL) was used as secondary antibody. Cells were washed three times with PBS and incubated with $0.4 \mathrm{mg} / \mathrm{ml}$ orthophenylenediamine $+0.00012 \% \mathrm{H}_{2} \mathrm{O}_{2}$. The enzymatic reaction was stopped with $50 \mu \mathrm{l} 2 \mathrm{M}$ $\mathrm{H}_{2} \mathrm{SO}_{4}$. Absorbance was immediately determined at a wavelength of $492 \mathrm{~nm}$ on an ELISA reader (Molecular Devices, Sunnyvale, CA).

\section{RNA Isolation and Northern Blots Analysis}

Confluent HUVEC were left untreated or infected with rAdCD39 or $\operatorname{rAd} \beta$ gal for $48 \mathrm{hr}$ and stimulated with thrombin, ATP $\gamma \mathrm{S}$, ATP, ADO; peak levels of E-selectin RNA were observed at $4 \mathrm{hr}$. RNA were isolated using RNeasy Mini Kit (Qiagen GmbH, Hilden, Germany) according to the manufacturer's instructions. The amount of extracted RNA was calculated from optical density (O.D.) measurements at $260 \mathrm{~nm}$. Equal amounts of total RNA $(5 \mu \mathrm{g})$ were loaded and run on a $1.3 \%$ agarose formaldehyde gel, transferred overnight to Hybond-N nylon membranes 
(Amersham NEN Life Science, Boston, MA), and analyzed by specific hybridization to radiolabeled cDNA probes for human E-selectin (a kind gift from Dr. T. Collins, Brigham and Women's Hospital, Harvard Medical School, Boston, MA) and glyceraldehyde-3-phosphate dehydrogenase as an internal control (GADPH) (20).

\section{Electrophoretic Mobility Shift Assay (EMSA)}

Confluent HUVEC were left untreated, or infected with rAdCD 39 or $\mathrm{rAd} \beta$ gal for $48 \mathrm{hr}$ and, subsequently, stimulated with ATP or ATP $\gamma S$ at the previously defined high concentrations for $\mathrm{l}$ hr to activate NF- $\mu \mathrm{B}$ (22). Nuclear proteins were extracted from HUVEC by high salt extraction as described (20). All buffers were supplemented with $1 \mu \mathrm{g} / \mathrm{ml}$ leupeptin, $1 \mu \mathrm{g} / \mathrm{ml}$ aprotinin, $1 \mu \mathrm{g} / \mathrm{ml}$ phenylmethysulfonyl fluoride (PMSF), 0.1 mM N- $\alpha$-Tosyl-L-lysine chloromethyl ketone (TLCK) and $0.1 \mathrm{mM}$ Tosyl-L-phenylalanine chloromethyl ketone (TPCK). Equal amounts of nuclear extracts $(5 \mu \mathrm{g})$ were incubated $30 \mathrm{~min}$ at room temperature with $120,000 \mathrm{cpm}$ of ${ }^{32} \mathrm{P}$ - $\gamma$-ATP radiolabeled NF- $\kappa$ B-specific oligonucleotide (5'AGTTGAGGG-AATTTCCCAGGC-3'), $3 \mathrm{mg}$ of poly (dI-dC) in $20 \mathrm{mM}$ HEPES, pH 7.9, $50 \mathrm{mM}$ $\mathrm{NaCl}, 1 \mathrm{mM}$ EDTA, $1 \mathrm{mM} \beta$-mercaptoethanol, and $5 \%$ glycerol. The resulting DNA/protein complexes were separated on a $6 \%$ polyacrylamide gel in Tris glycine/EDTA buffer at pH 8.5 and finally subjected to autoradiography on Kodak film (Kodak, Rochester, NY).

\section{Apoptosis Assay}

Cell death by apoptosis induced by ATP was assessed by flow cytometric analysis of DNA content following propidium iodide staining (20). Confluent HUVEC were left untreated, or infected with rAdCD39 or rAd $\beta$ gal for $48 \mathrm{hr}$, and incubated with staurosporine $200 \mathrm{nM}$ (as the positive control) ATP or ATP $\gamma S$ for $18 \mathrm{hr}$ in 10\% FCS M199, 10 mM HEPES. Cells were harvested by trypsin digestion, washed with PBS, and then fixed in $70 \%$ ethanol. Cells were suspended in PBS, pH 7.4, containing $0.1 \%$ triton X-100, 0.1 mM EDTA, pH 7.4, with 50 $\mu \mathrm{g} / \mathrm{ml} \mathrm{RNAase} \mathrm{A,} 50 \mathrm{U} / \mathrm{mg}$, and $50 \mu \mathrm{g} / \mathrm{ml}$ propidium iodide, and incubated for $1 \mathrm{hr}$. Finally, cells were analyzed by flow cytometry on a FACSort equipped with Cellquest II software (Becton Dickinson, Franklin Lakes, NJ) to determine percentage of nuclei with hypodiploid content indicative of apoptosis. Cellular debris and doublets were excluded from analysis by gating by forward and right side light scatter properties.

\section{Results}

Adenoviral Gene Transfer of CD39 in HUVEC Substantively Increased NTPDase Activity

Confluent monolayers of HUVEC were infected for $48 \mathrm{hr}$ with rAdCD39, $\mathrm{rAd} \beta$ gal, or left untreated. To evaluate the efficiency of recombinant CD39 adenoviral infection in HUVEC, we determined NTPDase activity by the measurement of inorganic phosphate release from exogenous ATP. Expression of CD39 was confirmed by immunocytochemistry and Western blots analysis following five series of infections (not shown). In a representative experiment, the $\operatorname{rAd} \beta$ gal-infected HUVEC expressed NTPDase activity of $1.01 \pm 0.02 \mathrm{Pi}$ nmole $/ \mathrm{min} /$ well; whereas, the control non-infected HUVEC had basal levels of $0.95 \pm 0.002 \mathrm{Pi}$ nmole/min/well. The rAdCD 39 infection of HUVEC resulted in a 14-fold higher biochemical activity of $14.50 \pm$ 3.50 Pi nmole/min/well that remained consistently elevated in subsequent experiments (not shown). We did not attempt to measure supernatant fluid content of ATP at the various timepoints tabulated below when the various experimental end-points were determined.

Type I EC Activation:

von Willebrand Factor Secretion

Determination of von Willebrand factor (vWF) release from Weibel-Palade bodies was used as an index of immediate EC P2Y-mediated activation response to extracellular adenine nucleotides. Confluent monolayers of CD39, $\beta$-galactosidase-infected, or non-infected HUVEC were maintained in 24-well plates and stimulated with thrombin (1 U/ml), ATP $\gamma S$ $(50 \mu \mathrm{M})$, ATP $(50 \mu \mathrm{M})$, and adenosine $(50 \mu \mathrm{M})$ for 60 min under serum-free conditions, on three separate occasions. Conditioned media were then tested for vWF antigen levels by ELISA. Dose response curves were performed that were similar to published data [(13); not shown].

In a experiment representative of three, nonstimulated HUVEC had basal levels of vWF release of $0.59 \pm 0.01 \mathrm{mU} / \mathrm{ml}$ from noninfected cells, $0.85 \pm 0.04 \mathrm{mU} / \mathrm{ml}$ from $\operatorname{rAd} \beta$ gal-infected, and $0.89 \pm 0.01 \mathrm{mU} / \mathrm{ml}$ from rAdCD39-infected cells. We noted that high levels of thrombin stimulation increased by 11-fold the amount of vWF released, to $6.49 \pm 0.01 \mathrm{mU} / \mathrm{ml}$, from non-infected cells. In 
addition, the vWF released from $\mathrm{rAd} \beta$ galinfected EC was $7.13 \pm 0.75 \mathrm{mU} / \mathrm{ml}$; whereas, a comparable increase to $7.99 \pm 0.33 \mathrm{mU} / \mathrm{ml}$ was observed in the rAdCD39-infected EC cultures stimulated with high levels of thrombin. The non-hydrolysable ATP-analog, ATP $\gamma \mathrm{S}$, resulted in a 7-fold increase in vWF secretion to $3.89 \pm$ $0.01 \mathrm{mU} / \mathrm{ml}$ from non-infected cells; whereas, comparable increases to $4.22 \pm 0.18$ and $4.71 \pm$ $0.39 \mathrm{mU} / \mathrm{ml}$ were noted in $\mathrm{rAd} \beta \mathrm{gal}-$ and rAdCD39-infected cells, respectively (Fig. 1). Most importantly, stimulation of HUVEC with extracellular ATP resulted in a 6-fold increase of vWF release to $3.61 \pm 0.03 \mathrm{mU} / \mathrm{ml}$ from noninfected cells. Although a comparable increase was noted to $4.75 \pm 0.82 \mathrm{mU} / \mathrm{ml}$ in the $\mathrm{rAd} \beta$ gal-infected cultures, minimal increases to $1.87 \pm 0.06 \mathrm{mU} / \mathrm{ml}$ were consistently observed in the rAdCD39-infected EC cultures stimulated with ATP under the same experimental conditions. Under these experimental conditions, almost all of the extracellular ATP would be subjected to hydrolysis by $10 \mathrm{~min}$. Hence, overexpression of CD39 in HUVEC resulted in a $61 \%$ decrease in vWF secretion induced by ATP, compared with rAd $\beta$ galinfected cells $(p<0.005)$. In keeping with prior work (13), there were no differences in the multimer composition of the secreted vWF in response to either ATP or thrombin. In addition, the secreted vWF multimer patterns were comparable between both $\operatorname{rAd} \beta$ gal- and rAdCD39-infected cells (data not shown). Adenosine treatment doubled the levels of vWF secretion to $1.23 \pm 0.01 \mathrm{mU} / \mathrm{ml}$ from noninfected cells, to $1.45 \pm 0.04 \mathrm{mU} / \mathrm{ml}$ from $\operatorname{rAd} \beta$ gal infected and to $1.79 \pm 0.20 \mathrm{mU} / \mathrm{ml}$ from rAdCD39-infected cells (Fig. 1).

\section{Type II EC Activation: E-selectin Surface Expression}

We next tested whether ATP-induced type II activation, mediated at least in part by P2X7-receptors, could be influenced by high levels of CD39 expression. We examined levels of E-selectin surface expression and up-regulation on confluent monolayers of HUVEC in 96-well plates. Experiments were timed to facilitate maximal synthesis and expression of E-selectin with concurrent loss of P-selectin

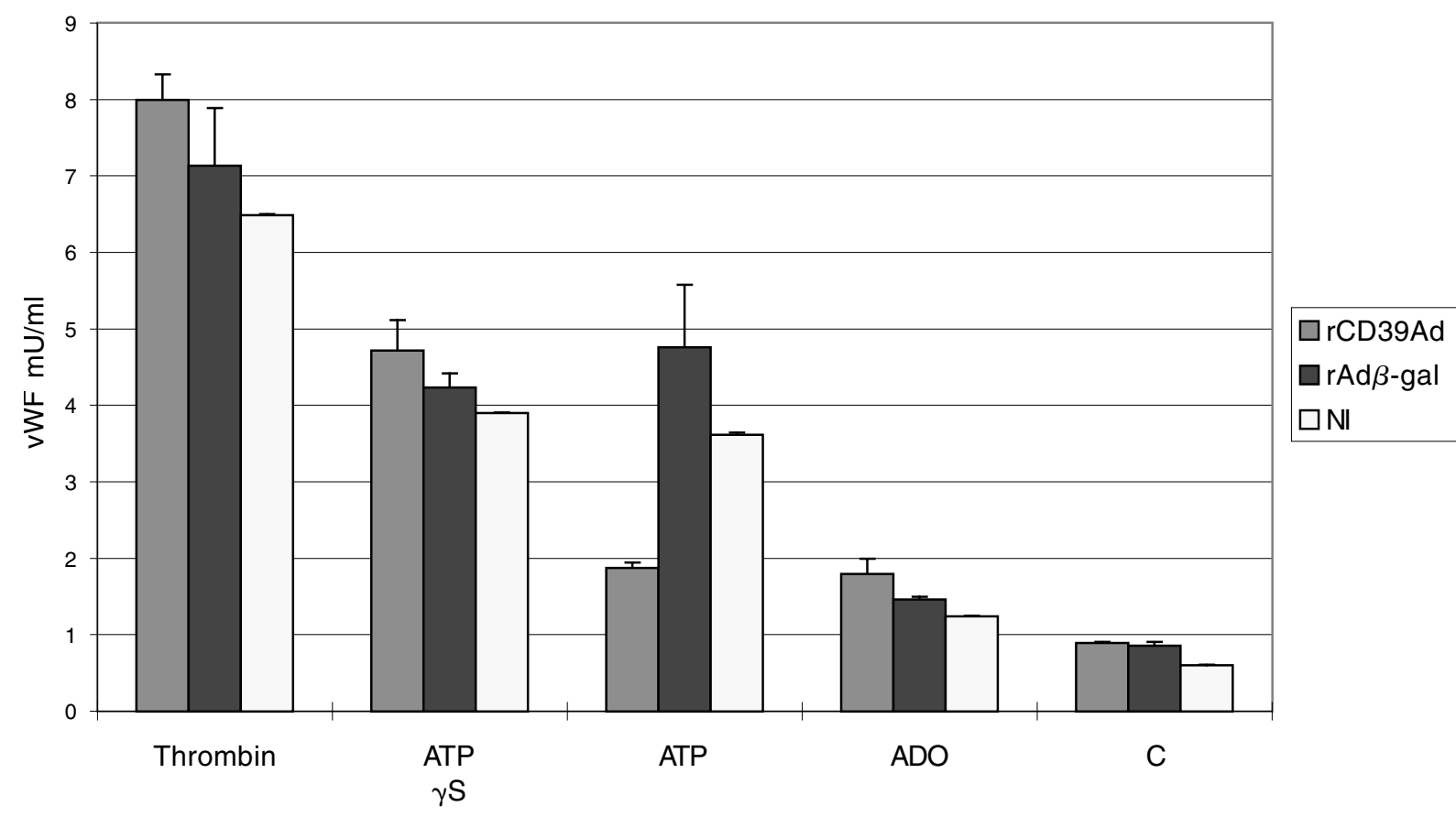

Fig. 1. CD39 decreases ATP-induced von Willebrand (vWF) release. HUVEC were grown to confluency in 24-well plates, left untreated or infected with CD39 or $\beta$-galactosidase adenovirus. Confluent cells were incubated with thrombin, ATP, ATP $\gamma \mathrm{S}$, or adenosine (ADO). vWF release was measured in conditioned serum-free medium, taken 60 min after stimulation by ELISA. Overexpression of
CD39 limited ATP-induced vWF secretion by approximately $60 \%$. Experiments were performed in triplicate and results are expressed as mean \pm SEM. C, control; NI, non-infected; rAdCD39, recombinant replication-deficient adenovirus from human CD39 cDNA; rAd $\beta$ gal, recombinant replication-deficient adenovirus from bacterial $\beta$-galactosidase. 
from the EC $(20,37)$. Cells were stimulated by a 12-hr incubation with thrombin $(10 \mathrm{U} / \mathrm{ml})$, ATP $\gamma S(5 \mathrm{mM})$, ATP (5 mM), and adenosine (5 $\mathrm{mM})$. This was done on three separate occasions and data are presented from a representative study. Thrombin treatment of HUVEC consistently resulted in an approximate 7 -fold induction of immunoreactive E-selectin expression in non-infected cells $(0.17 \pm 0.01$ to $1.22 \pm$ $0.04)$, with comparable increments in $\operatorname{rAd} \beta$ galinfected cells $(0.19 \pm 0.01$ to $1.39 \pm 0.03)$ and in rAdCD39-infected cells $(0.17 \pm 0.02$ to 1.20 $\pm 0.01)$. This showed that these pathways were largely independent of high levels of CD39 expression (Fig. 2). ATP $\gamma S$ stimulation of HUVEC substantively increased E-selectin surface expression in non-infected cells $(0.17 \pm 0.01$ to $1.13 \pm 0.03)$, with comparable approximate 6fold increments in $\operatorname{rAd} \beta$ gal-infected cells $(0.19$ \pm 0.01 to $1.19 \pm 0.07)$ and in rAdCD39-infected cells $(0.17 \pm 0.02$ to $1.12 \pm 0.07)$. In the parallel experiments, ATP treatment of non-infected HUVEC resulted in only an approximate 5 -fold induction of E-selectin surface expression in non-infected cells $(0.17 \pm 0.01$ to $0.81 \pm 0.08)$, a comparable induction in $\mathrm{rAd} \beta$ gal-infected cells $(0.19 \pm 0.01$ to $0.87 \pm 0.08)$, but only a doubling in rAdCD39-infected cells $(0.17 \pm$ 0.02 to $0.37 \pm 0.01 ; p<0.005$; Fig. 2). Adenosine stimulation of HUVEC had no effects on boosting E-selectin surface expression in any of the EC cultures $(0.17 \pm 0.01$ to $0.17 \pm 0.01$ in non-infected cells, $0.19 \pm 0.01$ to $0.18 \pm 0.01$ in $\mathrm{rAd} \beta$ gal-infected cells, and $0.17 \pm 0.02$ to $1.18 \pm 0.01$ in rAdCD39-infected cells; Fig. 2). We, therefore, observed no differences in the specific E-selectin surface expression patterns in either thrombin or ATP $\gamma \mathrm{S}$-treated HUVEC, following up-regulation of CD39 post adenoviral infection. However, rAdCD39-infected HUVEC failed to respond to ATP treatment, with respect to the induction of E-selectin. Overexpression of $\mathrm{CD} 39$ resulted in substantial inhibition of ATP-induced E-selectin surface expression, compared with $\mathrm{rAd} \beta$ gal infected EC (Fig. 2).

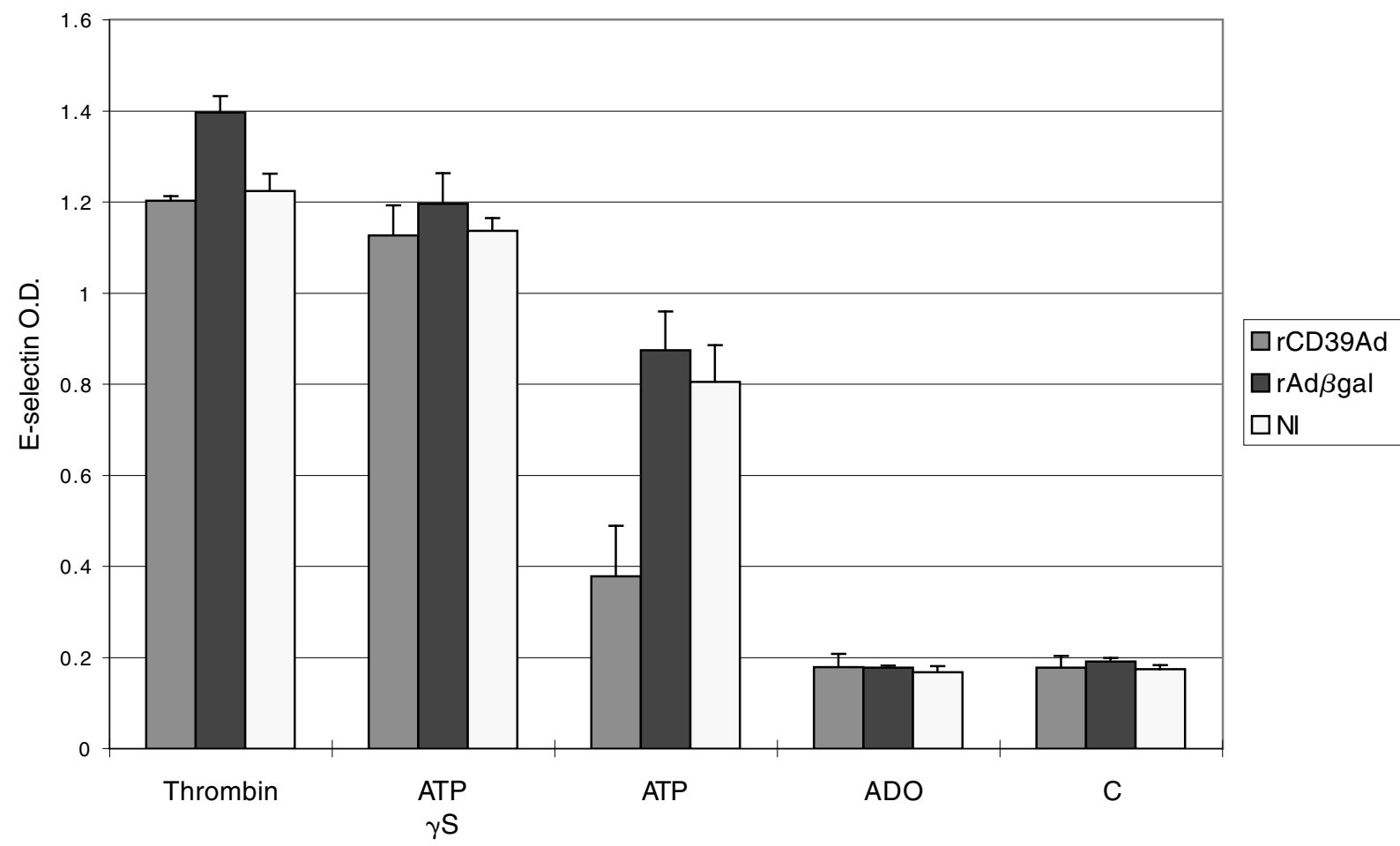

Fig. 2. CD39 inhibits ATP-induced E-selectin surface expression. Confluent human umbilical vein endothelial cells (HUVEC) were left untreated or infected with CD39 or $\beta$-galactosidase adenovirus. Cells were then stimulated with thrombin, ATP $\gamma \mathrm{S}, \mathrm{ATP}$, or adenosine for $12 \mathrm{hr}$. E-selectin surface expression was determined by ELISA, in triplicates of the cultures. Overexpression of CD39 approximately halved ATP-induced E-selectin surface expression. Results are expressed as mean \pm SEM of an experiment representative of three. C, control; NI, non-infected; rAdCD39, recombinant replication-deficient adenovirus from human CD 39 cDNA; rAd $\beta$ gal, recombinant replicationdeficient adenovirus from bacterial $\beta$-galactosidase. 


\section{E-selectin Gene Up-regulation}

Northern blots analysis was performed to study the transcriptional modulation of E-selectin in the infected HUVEC, following their stimulation with thrombin and several nucleotides. Total RNA was prepared $4 \mathrm{hr}$ after stimulation of HUVEC with thrombin (1-10 $\mathrm{U} / \mathrm{ml}), \operatorname{ATP} \gamma \mathrm{S}$ (1-5 mM), ATP (1-5 mM), and adenosine (1-5 $\mathrm{mM})$. High levels of thrombin and ATP $\gamma S$ consistently increased levels of E-selectin transcripts in non-infected, rAd $\beta$ galand rAdCD39-infected HUVEC, on three separate occasions. Adenosine had no effect on the transcription of E-selectin in these groups. However, levels of E-selectin transcripts were increased substantively $4 \mathrm{hr}$, only after ATP stimulation in non-infected and rAd $\beta$ galinfected HUVEC. By contrast, in the rAdCD39infected HUVEC, lower levels of mRNA transcripts for E-selectin were observed post-ATP stimulation (Fig. 3).

We also observed that, despite equal loading of $5 \mu \mathrm{g}$ of total intact RNA per lane, the GAPDH signal was lost with high levels of ATP-stimulation in cells, other than those over expressing CD39.

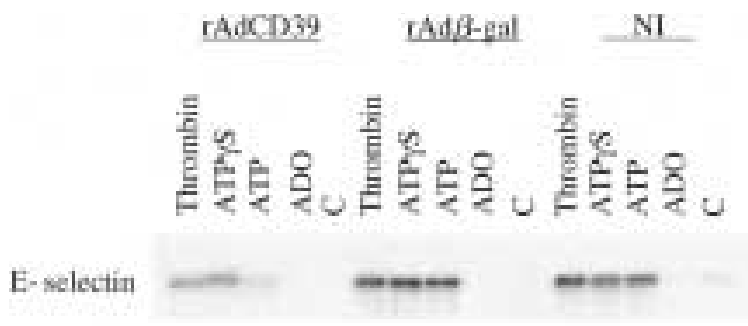

GAPDH

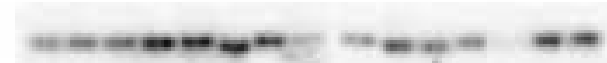

Fig. 3. CD39 decreases ATP-induced E-selectin mRNA levels. Up-regulation of mRNA encoding for E-selectin was evaluated by Northern blots analysis in non-infected, $\beta$-galactosidase, or CD39 adenovirus-infected human umbilical vein endothelial cells (HUVEC) that were stimulated with thrombin, ATP $\gamma S$, ATP, or adenosine (ADO) for $4 \mathrm{hr}$ ATP-, but not ATP $\gamma \mathrm{S}$-induced E-selectin gene up-regulation was abrogated by CD39. Results shown are representative of three independent experiments and include the control glyceraldehyde-3-phosphate dehydrogenase (GAPDH). C, control; NI, non-infected; rAdCD39, recombinant replication-deficient adenovirus from human CD39 cDNA; rAd $\beta$ gal, recombinant replication-deficient adenovirus from bacterial $\beta$-galactosidase.
Translocation of NF- $\kappa B$ to the Nucleus

Electrophoretic mobility shift assays were performed to confirm that the decreased ATP-induced E-selectin gene expression in rAdCD39-infected HUVEC was associated with failure of transcription factor NF- $\kappa$ B activation and nuclear targeting. Nuclear extracts were prepared from non-infected, $\operatorname{rAd} \beta$ galand rAdCD39-infected HUVEC, after l hr stimulation with ATP $(5 \mathrm{mM})$ or ATP $\gamma \mathrm{S}(5$ $\mathrm{mM})$. After incubation with a ${ }^{32} \mathrm{P}$-labeled oligodeoxynucleotide encoding the NF- $\kappa \mathrm{B}$ binding site, the protein/DNA complexes were analyzed to determine NF- $\kappa \mathrm{B}$ activation. Mutant and a cold NF- $\kappa$ B competitor (as internal controls) were co-incubated with the ATPstimulated nuclear extracts from non-infected cells to demonstrate specificity for the $\kappa \mathrm{B}$ binding site. Nuclear extracts from ATP $\gamma S$ induced HUVEC had comparable levels of $\mathrm{NF}-\kappa \mathrm{B}$ activation and nuclear translocation in all three groups of cells. However, when ATP was used as the agonist, there was markedly less $\kappa \mathrm{B}$-binding activity observed in the nuclei of rAdCD39-infected HUVEC, compared with rAd $\beta$ gal-infected or non-infected HUVEC (Fig. 4). These data were consistent in three experiments, since all demonstrated decreased transcriptional activity of NF- $\kappa \mathrm{B}$-dependent genes, upon ATP stimulation in rAdCD39infected HUVEC.

\section{Apoptotic Cell Death}

In addition to the modulating effects of CD39 on type I and type II activation detailed above, we also examined regulation of ATP-mediated cell death by CD39. HUVEC were infected with rAdCD39, $\operatorname{rAd} \beta$ gal, or left untreated. Individual cell cultures were then incubated with staurosporine $(200 \mathrm{nM})$, ATP $\gamma \mathrm{S}(5 \mathrm{mM})$ or ATP (5 mM) for $18 \mathrm{hr}$. To confirm apoptotic cell death, DNA fragmentation was determined by propidium iodide (PI) labeling, followed by flow cytometric measurement of the percentage of nuclei with hypodiploid DNA content. Two regions were defined within a flow cytometric cell cycle histogram. The first region designated $\mathrm{Ml}$, including a major diploid peak $\left(G_{0} / G_{1}\right)$, as well as a small hyperdiploid region (S) and a tetraploid region $\left(\mathrm{G}_{2} / \mathrm{M}\right)$. The second region, designated $M 2$, was adjacent to the $\mathrm{G}_{0} / \mathrm{G}_{1}$ peak and included cells undergoing apoptosis-associated DNA fragmentation. In a representative study of four untreated, non- 


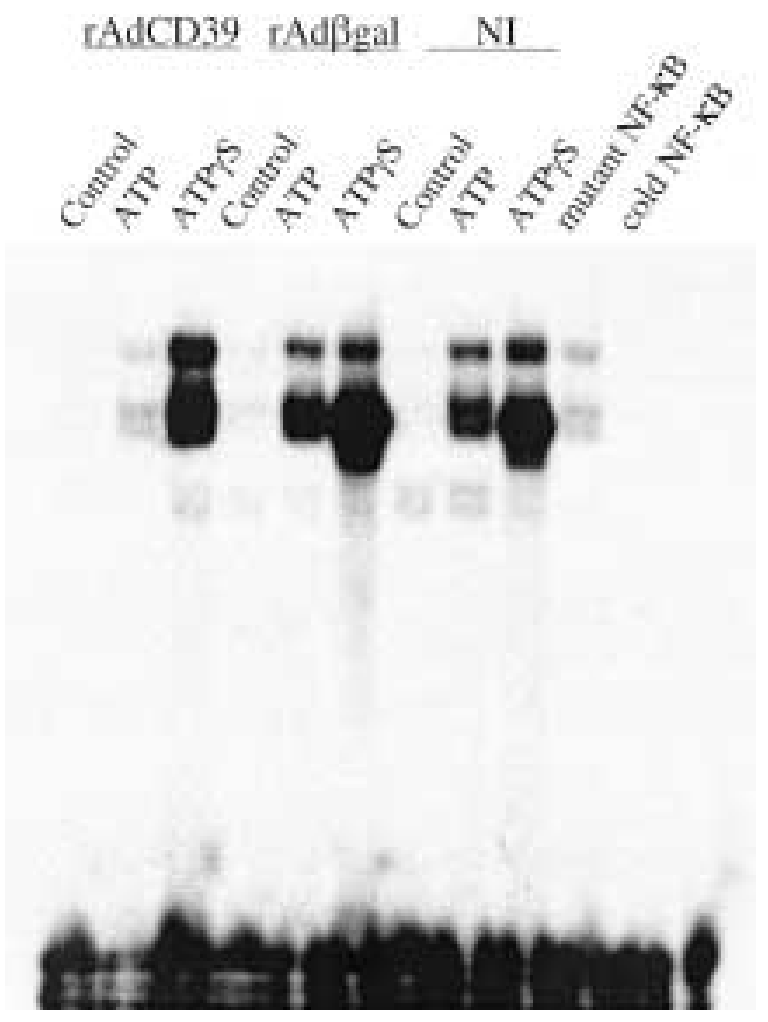

Fig. 4. CD39 abrogates ATP induced nuclear factor (NF) $-\kappa B$ translocation. Confluent human umbilical vein endothelial cells (HUVEC) were left untreated or infected with CD39 or $\beta$-galactosidase adenovirus, and subsequently, stimulated with ATP or ATP $\gamma$ S. Nuclear proteins were extracted from HUVEC and equal amounts of nuclear extracts were incubated with a radiolabeled NF- $\kappa \mathrm{B}$-specific oligonucleotide. Resulting DNA/protein complexes were separated by electrophoretic mobility shift assay (EMSA) on a $6 \%$ polyacrylamide gel. Controls with competing unlabeled or mutated probes for NF- $\kappa$ B confirmed specificity. One experiment, representative of three, is shown and confirms that CD39 up-regulation blocked the ATP-mediated NF- $\kappa$ B translocation. NI, non-infected; rAdCD39, recombinant replication-deficient adenovirus from human CD39 cDNA; rAd $\beta$ gal, recombinant replicationdeficient adenovirus from bacterial $\beta$-galactosidase.

infected HUVEC, 1-2\% of cells were observed to be in the M2 region. The basal $\mathrm{rAd} \beta$ gal- and rAdCD39-infected HUVEC cultures had $8 \%$ and $4 \%$ of cells in the $\mathrm{M} 2$ region, respectively. Staurosporine treatment of HUVEC resulted in $75-85 \%$ apoptotic cells in all groups. Exposure to ATP $\gamma \mathrm{S}$ killed $65 \%$ of non-infected cells, $67 \%$ of $\operatorname{rAd} \beta$ gal-infected cells, and $66 \%$ of rAdCD39-infected cells no significant (NS) difference. When incubated with ATP, non-infected HUVEC cultures sustained $57 \%$ apoptosis rates, rAd $\beta$ gal-infected HUVEC had $60 \%$ apoptotic cells, but rAdCD39-infected HUVEC were somewhat protected, with only $21 \%$ of cells undergoing apoptosis, as observed in this representative experiment (Fig. 5). Overexpression of CD39 in HUVEC substantively decreased the extent of ATP-induced apoptosis, compared with HUVEC infected with rAd $\beta$ gal. In these series of experiments, ATP $\gamma \mathrm{S}$ or ATP concentrations below $5 \mathrm{mM}$ were largely ineffective at inducing substantive levels of apoptosis in HUVEC, further suggesting involvement of the P2X7-receptor (data not shown).

\section{Discussion}

Activation responses, induced by nucleotides released into the plasma, have the potential to influence vasomotor responses, platelet aggregation, thrombotic reactions and inflammatory processes (22,38-40). Extracellular ATP and ADP appear to regulate hemostasis and platelet microthrombus formation through the modulation of several platelet P2 receptors (41-45). The removal of an extracellular $\mathrm{P} 2 \mathrm{Y} 1$ receptor agonist, ADP by vascular EC NTPDase activity, has demonstrable thromboregulatory effects on platelet activation responses (2) that also encompass maintenance of the $\mathrm{P} 2 \mathrm{Yl}$ receptor function (26).

ATP and ADP also stimulate EC P2Y receptors to induce release of prostacyclin and NO $(12,24,46-48)$. In addition, ATP also exhibits various immediate or delayed activationrelated effects on EC, including plasma membrane permeabilization, induction of apoptosis and stimulation of $\mathrm{Ca}^{2+}$ mobilization with $\mathrm{NF}-\kappa \mathrm{B}$ translocation to the nucleus $(20,39,49)$. The fully ionized tetrabasic form of ATP (viz. $\mathrm{ATP}^{4-}$ ) that interacts with the unique P2Z/P2X7 receptors that are typically located on monocyte-macrophages $(\mathrm{M} \phi)(22,50)$ is also considered to activate EC via this pathway $(4,20)$.

Prior to this study, modulatory influences on purinergic signaling have not been demonstrated for the vascular endothelium and the direct effects of the loss of NTPDase function post-cellular activation have been unclear (25). CD39/cd39 account(s) for almost all NTPDase biochemical activity in the vascular endothelium. An ectoATPase or -NTPase is also expressed by EC and is identical with cd39LI $(26,51)$. The localization of CD39 to caveolae, membrane microdomains that also have high concentrations of G-protein coupled receptors (52), further suggests involve- 


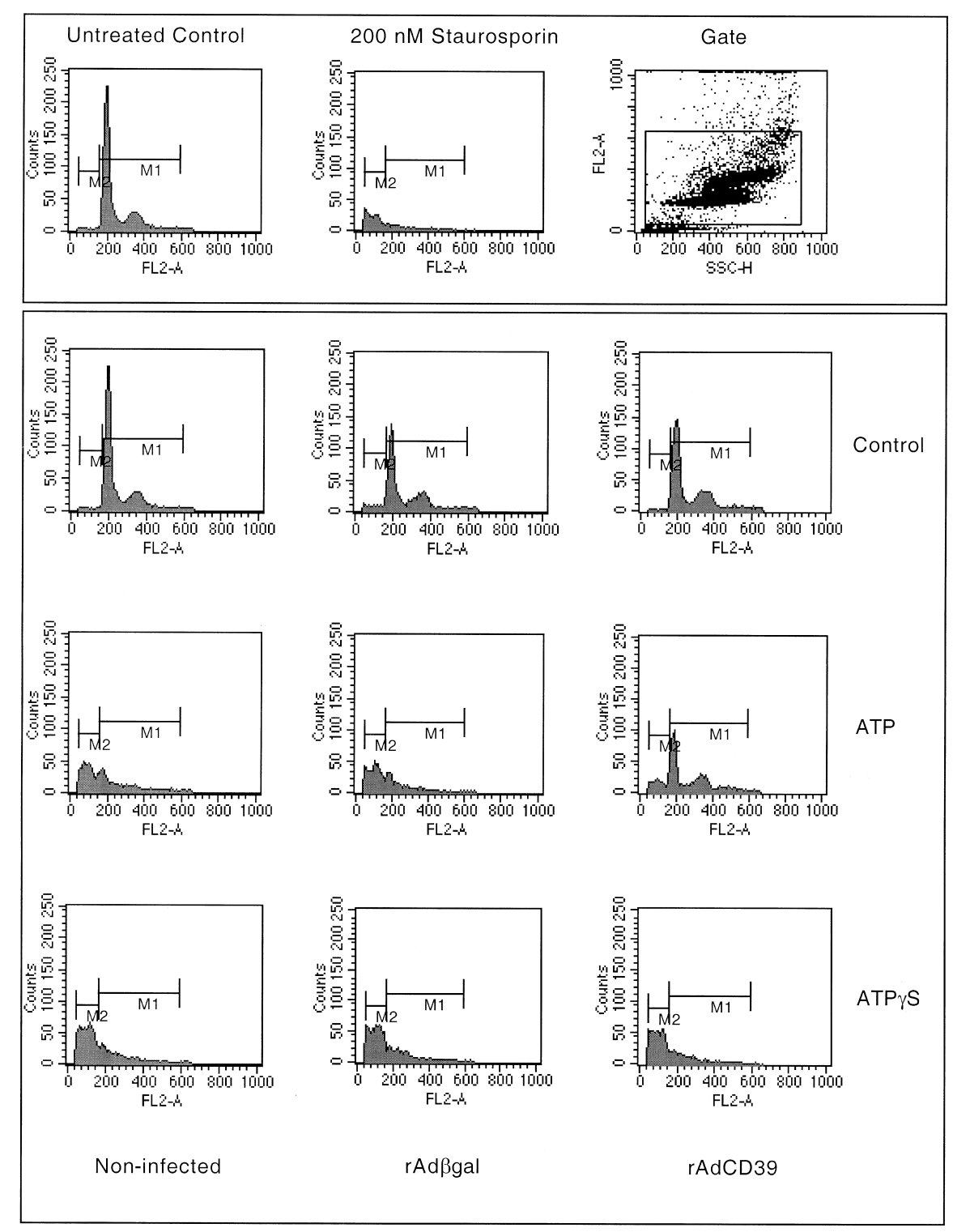

Fig. 5. Overexpression of CD39 inhibits ATPinduced apoptosis. Confluent human umbilical vein endothelial cells (HUVEC) were left untreated or infected with CD39 or $\beta$-galactosidase adenovirus. Groups of cells were then left untreated or incubated with staurosporine (200 nM), ATP (5 mM), or ATP $\gamma S$

ment of the vascular NTPDase in cellular activation responses directly triggered by high levels of pericellular nucleotides (1).

CD39 is regulated by inflammatory stimuli and mediators in a post-translational manner that theoretically could influence processes of primary vascular injury $(25,53)$. However, it is possible that, at certain concentrations in the immediate pericellular environment, adenine nucleotides could preferentially interact with $\mathrm{P} 2$ receptors, rather than the ectonucleotidases expressed by the same cell. This may preclude
(5 mM). Cell apoptosis rates were assessed by flow cytometric analysis of DNA content by propidium iodide (PI) staining. ATP-induced apoptosis was decreased in rAdCD39-infected cells. FL2-A, forward light scatter; M1, viable cells; M2, nonviable cells.

efficient hydrolysis of nucleotides by the vascular NTPDases.

We demonstrated that stable and targeted overexpression of CD39 can be achieved by recombinant adenoviral infection. This consequent dramatic up-regulation of vascular NTPDase activity substantively influences nucleotide mediated activation pathways in EC both in vitro and in vivo. Our experimental data also demonstrate that the biochemical action of CD39 takes precedence over the interaction of nucleotides with $\mathrm{P} 2$ receptors at the cell surface. 
The secretion of vWF from Weibel-Palade bodies occurs independently of de novo protein synthesis and has been shown to be rapidly triggered by G-protein-coupled P2Y receptor ligation (13). In our experiments, adenosine alone had minimal effects on vWF release (Fig. 1). The major consequence of CD39 overexpression was to block substantively the release of VWF in response to hydrolysable forms of ATP and to abrogate an important type-I activation response (54) to nucleotides in vitro.

Type II EC activation has been considered to represent increased or de novo expression of proinflammatory factors, including the leukocyte adhesion molecule E-selectin $(17,54)$. Overexpression of vascular NTPDase was shown to decrease ATP-induced E-selectin surface expression on $\mathrm{EC}$, a NF- $\kappa \mathrm{B}$ dependent process, putatively related to $\mathrm{P} 2 \mathrm{X} 7$ activation $(20,21)$. By contrast, E-selectin surface expression levels induced by ATP $\gamma S$ are not influenced by recombinant adenoviral infection (Fig. 2). We also demonstrated that this failure of E-selectin induction was associated with transcriptional regulation (Fig. 3) and inhibition of ATP-induced translocation of the transcription factor NF- $\kappa$ B to the nucleus (Fig. 4). Our data, therefore, emphasize a potentially important role of CD39 in influencing ATPmediated type II EC activation and the consequent synthesis of adhesion receptors. In addition, CD39 would be anticipated to influence other activation responses to other agonists, such as endotoxin (55), that elicit ATP or ADP release from cells or platelets (56).

The ligation of $\mathrm{P} 2 \mathrm{X} 7$ receptors that are ligand-gated cation channels by specific nucleotide agonists results in apoptosis $(20-22,50)$. EC apoptotic reactions that were observed following exposure to high levels of ATP could be attenuated by overexpression of CD39, following infection with rCD39Ad (Fig. 5). Under these experimental conditions, the use of GAPDH as an internal control gene, may be inappropriate (not shown). This observation that CD39 influences cell death has relevance to the further induction of a pro-thrombotic state $(57,58)$ and the release of proinflammatory cytokines, like interleukin-1 (IL-1) (59).

These experiments, taken in their entirety, indicate that various biological functions exerted by extracellular ATP, including type I and type II activation as well as apoptosis, can be modulated by high levels of vascular NTPDase in vitro. Therefore, in an analogous manner to platelets, nucleotide-mediated signaling in vascular EC can be influenced by simultaneous exposure to NTPDases. Resistance to ATP action may be explained by the presence of high levels of CD39 that protect from the stimulatory effects of extracellular ATP by facilitating accelerated phosphohydrolysis to AMP.

To test whether adenoviral-mediated gene transfer could be an effective therapeutic modality in vivo, we also have infected guinea pig hearts with rCD39Ad or $\mathrm{rAd} \beta$ gal and transplanted these grafts into rats (60). Survival benefits were achieved in this model that were analogous to those seen with the administration of soluble NTPDases (34), or other antiplatelet interventions (61). These data, when taken in conjunction with the current observations, suggest that the thromboregulatory effects of CD39 are important for mediating those inflammatory reactions characterized by EC perturbation and cell death in vivo.

The physiological concentrations of ATP in plasma are thought to be between 0.4 and $6 \mu \mathrm{M}$, but local concentrations could increase dramatically after vascular injury and platelet degranulation into the $\mathrm{mM}$ range that we evaluated in this study in vitro $(11,62)$. In the light of this and because of current limitations in the development of truncated functional derivatives of CD39 (53,63-65), targeted local expression of CD39 may have advantages to parenteral administration of soluble NTPDases.

Studies from our group and others suggest that CD39 expressed by EC and the vasculature plays a pivotal role in platelet aggregation and activation responses both in vitro and in vivo $(2,3,26,66)$. In addition, we now show that overexpression of CD39 by EC can have therapeutic effects on intrinsic cellular activation processes and apoptosis induction by extracellular nucleotides.

\section{Acknowledgments}

CG is a recipient of a fellowship from the Deutsche Forschungsgemeinschaft. This work was supported by NIH R01 HL57307 and American Heart Association Grant in Aid 9650490N. SCR also thanks the MRC UCT Liver Center, Cape Town, South Africa for early research support that facilitated the current work. 


\section{References}

1. Kittel A, Kaczmarek E, Sevigny J, Lengyel K, Csizmadia E, Robson SC. (1999) CD39 as a caveolar-associated ectonucleotidase. Biochem. Biophys. Res. Comm. 262: 596-599.

2. Kaczmarek E, Koziak K, Sevigny J, et al. (1996) Identification and characterization of CD39 vascular ATP diphosphohydrolase. J. Biol. Chem. 271: 33116-33122.

3. Marcus AJ, Broekman MJ, Drosopoulos JHF, et al. (1997) The endothelial cell ecto-ADPase responsible for inhibition of platelet function is CD39. J. Clin. Invest. 99: 1351-1360.

4. Koziak E, Sevigny J, Robson SC, Siegel JB, Kaczmarek K. (1999) Analysis of CD39/ATP diphosphohydrolase expression in endothelial cells, platelets and leukocytes. Thromb. Haemost. 82: 1538-1544.

5. Zimmermann H. (1999) Two novel families of ectonucleotidases: molecular structure, catalytic properties and a search for function. TIPS $\mathbf{2 0}$ 231-236.

6. Zimmermann H. (1992) 5'-nucleotidase: molecular structure and functional aspects. Biochem. J. 285: 345-365.

7. Abbracchio MP, Burnstock G. (1994) Purinoceptors-are there families of P2X and P2Y purinoceptors [Review]. Pharmacol. Therap. 64: 445-475.

8. Cronstein BN, Bouma MG, Becker BF. (1996) Purinergic mechanisms in inflammation. Drug Develop. Res. 39: 426-435.

9. Barros LF, Yudilevich DL, Jarvis SM, Beaumont N, Young JD, Baldwin SA. (1995) Immunolocalisation of nucleoside transporters in human placental trophoblast and endothelial cells: evidence for multiple transporter isoforms. Pflugers. Archiv. Eur. J. Physiol. 429: 394-399.

10. Coade SB, Pearson JD. (1989) Metabolism of adenine nucleotides in human blood. Circ. Res. 65: 531-537.

11. Luthje J. (1989) Origin, metabolism and function of extracellular adenine nucleotides in the blood [published erratum appears in J. Klin. Wochenschr. (1989) 67: 558]. [Review]. J. Klin. Wochenschr. 67: 317-327.

12. Motte S, Communi D, Pirotton S, Boeynaems JM. (1995) Involvement of multiple receptors in the actions of extracellular ATP: the example of vascular endothelial cells. [Review]. Int. J. Biochem. Cell Biol. 27: 1-7.

13. Vischer UM, Wolheim CB. (1998) Purine nucleotides induce regulated secretion of von Willebrand factor. Blood. 91: 118-127.

14. Cotran RS, Pober, J. S. (1990) Cytokine-endothelial interactions in inflammation, immunity, and vascular injury. J. Amer. Soc. Nephrol. 1: 225-235.

15. Cotran RS, Pober JS. (1989) Effects of cytokines on vascular endothelium: their role in vascular and immune injury. Kidney Int. 35: 969-975.

16. Pober JS, Cotran RS. (1990) Cytokines and endothelial cell biology. Physiol. Rev. 70: 427-451.

17. Bach FH, Robson SC, Ferran C, et al. (1994) Endothelial cell activation and thromboregulation during xenograft rejection [Review]. Immunol. Rev. 141: 5-30.

18. Siebenlist U, Franzoso G, and Brown K. (1994) Structure, regulation and function of NF- $\kappa \mathrm{B}$. Annu. Rev. Cell Biol. 10: 405-455.

19. Baeuerle PA, Henkel T. (1994) Function and activation of NF- $\kappa \mathrm{B}$ in the immune system. Ann. Rev. Immunol. 12: 141-179.

20. Von Albertini M, Palmetshofer A, Kaczmarek E, et al. (1998) Extracellular ATP and ADP activate transcription factor NF- $\kappa-\mathrm{b}$ and induce endothelial cell apoptosis. Biochem. Biophys. Res. Comm. 248: 822-829.

21. Ferrari D, Wesselborg S, Bauer M, Schulze OK. (1997) Extracellular ATP activates transcription factor NF- $\kappa$ B through the P2Z purinoreceptor by selectively targeting NF- $\kappa$ B p65. J. Cell. Biol. 139: 1635-1643.

22. Franceschi C, Abbracchio MP, Barbieri D, et al. (1996) Purines and cell death. Drug Develop. Res. 39: 442-449.

23. Marcus AJ, Safier LB, Hajjar KA, Ullman HL, Islam N, Broekman MJ, Eiroa AM. (1991) Inhibition of platelet function by an aspirin-insensitive endothelial cell ADPase. Thromboregulation by endothelial cells. J. Clin. Invest. 88: 16901696.

24. Marcus AJ, Safier LB. (1993) Thromboregulation: multicellular modulation of platelet reactivity in hemostasis and thrombosis. [Review]. FASEB J. 7: 516-522.

25. Robson SC, Kaczmarek E, Siegel JB, et al. (1997) Loss of ATP diphosphohydrolase activity with endothelial cell activation. J. Exp. Med. 185: 153-163.

26. Enjyoji K, Sevigny J, Lin Y, et al. (1999) Targeted disruption of cd39/ATP diphosphohydrolase results in disordered hemostasis and thromboregulation. Nature Med. 5: 1010-1017.

27. Fabre JF, Nguyen M, Latour A, et al. (1999) Decreased platelet aggregation, increased bleeding time and resistance to thromboembolism in P2Y1-deficient mice. Nature Med. 5: 1199-1202.

28. Deguchi H, Takeya H, Urano H, Gabazza EC, Zhou H, Suzuki K. (1998) Adenosine regulates tissue factor expression on endothelial cells. Thrombosis Res. 91: 57-64.

29. Robson SC, Candinas D, Siegel JB, et al. (1996) Potential mechanism of abnormal thromboregulation in xenograft rejection-loss of ecto-ATPases upon endothelial cell activation. Transplantation Proc. 28: 536.

30. Candinas D, Koyamada N, Miyatake T, et al. (1996) Loss of rat glomerular ATP diphosphohydrolase activity during reperfusion injury is as- 
sociated with oxidative stress reactions. Thromb. Haemost. 76: 807-812.

31. Robson SC, Daoud S, Begin M, et al. (1997) Modulation of vascular ATP diphosphohydrolase by fatty acids. Blood Coagul. Fibrinolysis 8: 21-27.

32. Robson SC, Candinas D, Hancock WW, Wrighton C, Winkler H, Bach FH. (1995) Role of endothelial cells in transplantation. [Review]. Int.Arch. Allergy Immunol. 106: 305-322.

33. Bach FH, Winkler H, Ferran C, Hancock WW, Robson SC. (1996) Delayed xenograft rejection [Review]. Immunol. Today 17: 379-384.

34. Koyamada N, Miyatake T, Candinas D, et al. (1996) Apyrase administration prolongs discordant xenograft survival. Transplantation 62: 1739-1743.

35. Soares MP, Muniappan A, Kaczmarek E, et al. (1998) Adenovirus-mediated expression of a dominant negative mutant of P65/RelA inhibits proinflammatory gene expression in endothelial cells without sensitizing to apoptosis. J. Immunol. 161: 4572-4582.

36. Baykov AA, Evtushenko OA, Avaeva SM. (1988) A malachite green procedure for orthophosphate determination and its use in alkaline phosphatase-based enzyme immunoassay. Analyt. Biochem. 171: 266-270.

37. Winkler H, Stuhlmeier K, Cheng Q, Csizmadia V, Bach FH. (1994) Inhibition of E-selectin transcription by an $\alpha$-globulin. J. Cell. Biochem. 18A: 325.

38. Boeynaems J-M, Pearson JD. (1990) P2 purinoreceptors on vascular endothelial cells: physiological significance and transduction mechanisms. TIPS 11: 34-37.

39. Dubyak GR, Elmoatassim C. (1993) Signal transduction via P2-purinergic receptors for extracellular ATP and other nucleotides [Review]. Am. J. Physiol. 265: C577-C606.

40. Brake A, Schumacher M, Julius D. (1996) ATP receptors in sickness, pain and death. Chem. Biol. 3: 229-232.

41. Hechler B, Leon C, Vial C, et al. (1998) The $\mathrm{P} 2 \mathrm{y}(\mathrm{l})$ receptor is necessary for adenosine $5^{\prime}$ diphosphate-induced platelet aggregation. Blood 92: 152-159.

42. Jin JG, Kunapuli SP. (1998) Coactivation of two different $G$ protein-coupled receptors is essential for ADP-induced platelet aggregation. Proc. Nat. Acad. Sci. USA 95: 8070-8074.

43. Sun B, Li J, Okahara K, Kambayashi J. (1998) P2x(1) Purinoceptor in human plateletsmolecular cloning and functional characterization after heterologous expression. J. Biol. Chem. 273: 11544-11547.

44. Daniel JL, Dangelmaier C, Jin JG, Ashby B, Smith JB, Kunapuli SP. (1998) Molecular basis for ADP-induced platelet activation I-evidence for three distinct ADP receptors on human platelets. J. Biol. Chem. 273: 2024-2029.
45. Jin JG, Daniel JL, Kunapuli SP. (1998) Molecular basis for ADP-induced platelet activation the P2yl receptor mediates ADP-induced intracellular calcium mobilization and shape change in platelets. J. Biol. Chem. 273: 20302034.

46. Yang S, Cheek DJ, Westfall DP, Buxton IL. (1994) Purinergic axis in cardiac blood vessels. Agonist-mediated release of ATP from cardiac endothelial cells. Circ. Res. 74: 401-407.

47. Fisette PL, Denlinger LC, Proctor RA, Bertics PJ. (1996) Modulation of macrophage function by P2Y-purinergic receptors [Review]. Drug Develop. Res. 39: 377-387.

48. Juul B, Plesner L, Aalkjaer C. (1993) Effects of ATP and related nucleotides on the tone of isolated rat mesenteric resistance arteries. J. Pharmacol. Exp. Therap. 264: 1234-1240.

49. Chow SC, Kass G, Orrenius S. (1997) Purines and their roles in apoptosis. Neuropharmacology 36: 1149-1156.

50. Ferrari D, Chiozzi P, Falzoni S, et al. (1997) ATPmediated cytotoxicity in microglial cells. Neuropharmacology 36: 1295-1301.

51. Chadwick BP, Frischauf AM. (1997) Cloning and mapping of a human and mouse gene with homology to ecto-ATPase genes. Mammal. Gen. 8: 668-672.

52. Shaul PW, Anderson RGW. (1998) Role of plasmalemmal caveolae in signal transduction [Review]. Amer. J. Physiol. - Lung Cell. Mol. Physiol. 19: L843-L851.

53. Esch JSA, Sevigny J, Kaczmarek E, et al. (1999) Structural elements and limited proteolysis of CD39 influence ATP diphosphohydrolase activity. Biochemistry. 38: 2248-2258.

54. Cotran RS, Pober JS. (1989) Endothelial activation and inflammation. Prog. Immunol. 8: 747.

55. Ferrari D, Chiozzi P, Falzoni S, Hanau S, Divirgilio F. (1997) Purinergic modulation of interleukin-1- $\beta$ release from microglial cells stimulated with bacterial endotoxin. J. Exp. Med. 185: 579-582.

56. Griffiths RJ, Stam EJ, Downs JT, Otterness IG. (1995) ATP induces the release of IL-1 from LPS-primed cells in vivo. J. Immunol. 154: 2821-2828.

57. Bombeli T, Karsan A, Tait JF, Harlan JM. (1997) Apoptotic vascular endothelial cells become procoagulant. Blood 89: 2429-2442.

58. Bombeli T, Schwartz BR, Harlan JM. (1999) Endothelial cells undergoing apoptosis become proadhesive for nonactivated platelets. Blood 93: 3831-3838.

59. Nicholson DW, Thornberry NA. (1997) Caspaseskiller proteases [Review]. TIPS 22: 299-306.

60. Imai M, Takigami K, Guckelberger O, et al. (In press) Recombinant adenoviral mediated CD39 gene transfer prolongs cardiac xenograft survival. Transplantation August, 2000 in press. 
61. Candinas D, Lesnikoski BA, Hancock WW, et al. (1996) Inhibition of platelet integrin GPIIbIIIa prolongs survival of discordant cardiac xenografts. Transplantation 62: 1-5.

62. Traut TW. (1994) Physiological concentrations of purines and pyrimidines [Review]. Mol. Cell. Bioch. 140: 1-22.

63. Gayle RB, Maliszewski CR, Gimpel SD, et al. (1998) Inhibition of platelet function by recombinant soluble ecto-ATPase/CD39. J. Clin. Invest. 101: 1851-1859.
64. Wang TF, Ou Y, Guidotti G. (1998) The transmembrane domains of ectoapyrase (CD39) affect its enzymatic activity and quaternary structure. J. Biol. Chem. 273: 24814-24821.

65. Wang TF, Handa M, Guidotti G. (1998) Structure and function of ectoapyrase (CD39). Drug Develop. Res. 45: 245-252.

66. Matsumoto M, Sakurai Y, Kokubo T, et al. (1999) The cDNA cloning of human placental ecto-ATP diphosphohydrolases I and II. FEBS Letters 453: 335-340. 